NASA Technical Memorandum 101702

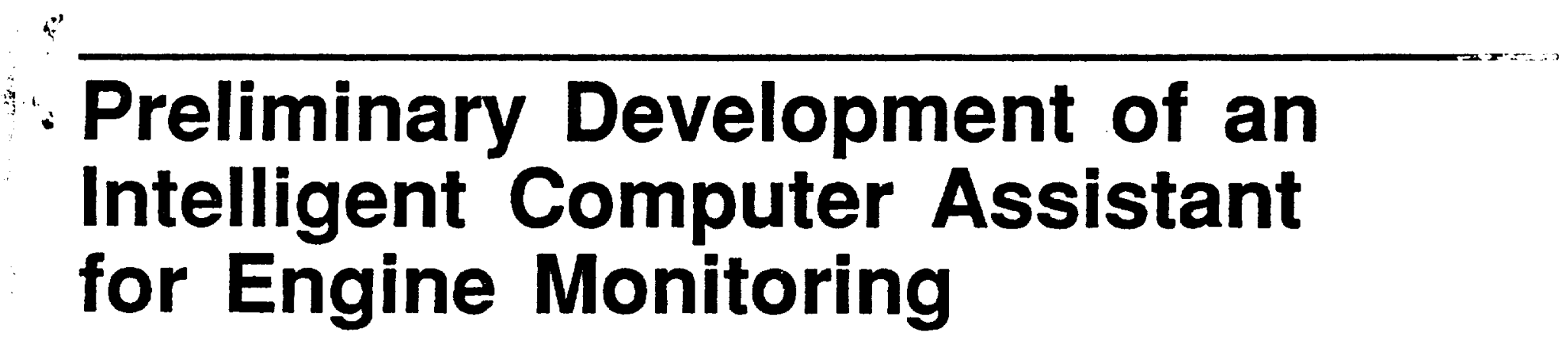

James D. Disbrow, Eugene L. Duke, and Ronald J. Ray

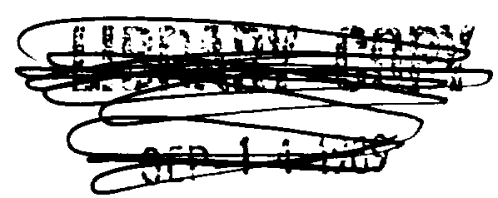

$1 \div$

August 1989

:1

LANGLEY RESEARCH CENTER HAMPRAON, VIRELINI

(NASA-TM-1017OL) PQELIMINARY JEVELOPMENT UF

$N 90-22322$

AN INTELLIGENT CCMPUTER ASSTSIANT FOR ENUINE MOVITRRITA (NASA) LO CSLL OYD

Unclas

$63 / 53 \quad 0279339$

\title{
N/SA
}

National Aeronautics and

Space Administration 
NASA Technical Memoradum 101702

\section{Preliminary Development of an Intelligent Computer Assistant for Engine Monitoring}

James D. Disbrow

PRC Systems Services, Inc., Edwards, California

Eugene L. Duke and Ronald J. Ray

Ames Research Center, Dryden Flight Research Facility, Edwards, California

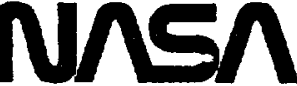

National Aeronautics and

Space Administration

Ames Research Center

Dryden Flight Research Facility

Edwards, California 93523-5000 



\title{
PRELIMINARY DEVELOPMENT OF AN INTELLIGENT COMPUTER ASSISTANT FOR ENGINE MONITORING
}

\author{
James D. Disbrow* \\ PRC Systems Services, Inc. \\ Aerospace Technologies Division \\ Edwards, Califomia \\ Eugene L. Duke ${ }^{\dagger}$ and Ronald J. Ray \\ NASA Ames Research Center \\ Dryden Flight Research Facility \\ Edwards, Califomia
}

\begin{abstract}
This paper presents the preliminary development of a method for monitoring the propulsion system and identifying correct recovery procedures for the F404 engine in support of the F-18 high-angle-of-attack research vehicle program. By using artificial intelligence techniques and modem display technology, we have been able to design a system that aids in real-time monitoring of propulsion systems. This expert system is designed to operate as an "expert aid" to an engineer with little or no experience in propulsion system monitoring. The goals of this expert system development project are to provide enhanced safety of flight and to relieve the propulsion engineers of the time-consuming but necessary task of propulsion system monitoring on flight programs, particularly those with nonexperimental engines. As telcmetry data is received, the results are continually being displayed to the engineer in a unique manner. The engincer has the choice of a number of different color graphical displays he may use. These include being able to monitor the engine state, monitor individual parameters and watch time histories or strip chart displays. When an anomaly is identified, that information is displayed to the engineer. Any additional information is also displayed, such as the procedures necessary to recover from the anomaly.

\footnotetext{
-Research Engineer.

'Chief Engineer, member AIAA.

'Propulsion Engincer.

Copyright $@ 1989$ by the American Institute of Acronautics and Astronautics, Inc. No copyright is asserted in the United States under Title 17, U.S. Code. The U.S. Government has a royalty-free license to exercise all rights under the copyright claimod herein for Governmental purposes. All other rights are reserved by the copyright owner.
}

Nomenclature

\begin{tabular}{|c|c|}
\hline A8 & nozzle area, $\mathrm{ft}^{2}$ \\
\hline CLIPS & C Language Production System \\
\hline CRT & cathode-ray tube \\
\hline ELube $P$ & engine lubrication pressure \\
\hline ICAEM & $\begin{array}{l}\text { intelligent computer assistant for engine } \\
\text { monitoring }\end{array}$ \\
\hline LVDT & linear voltage differential transformer \\
\hline N1 & rotational fan speed, percent or RPM \\
\hline N2 & $\begin{array}{l}\text { rotational compressor speed, percent } \\
\text { or RPM }\end{array}$ \\
\hline $\mathrm{Nz}$ & normal acceleration, $g^{\prime} s$ \\
\hline Pso & ambient static pressure, $1 \mathrm{~b} / \mathrm{in}^{2}{ }^{2}$ \\
\hline Ps3 & $\begin{array}{l}\text { compressor discharge static pressure, } \\
\mathrm{lb} / \mathrm{in}^{2}\end{array}$ \\
\hline PL5 & turbine discharge total pressure, $1 \mathrm{~b} / \mathrm{in}^{2}$ \\
\hline PLA & power lever angle position, deg \\
\hline $\mathbb{t} 1$ & inlet total temperature, $\mathrm{C}^{\circ}$ \\
\hline t5 & turbine discharge total temperature, $C^{\circ}$ \\
\hline
\end{tabular}

\section{Introduction}

Propulsion system monitoring is a flight safety function that is often performed for aireraft operating with experimental propulsion systems. Propulsion system monitoring may also be a safety-of-flight requirement for an aircraft performing extreme maneuvers or flying near the boundaries of the normal operating envelope.

At the Dryden Flight Reseanch Facility of the NASA Ames Research Center, this monitoring function is performed in the mission control center of the Westem Aeronautical Test Range. The task of propulsion system monitoring is normally performed by an experienced, senior-level propulsion system engineer familiar with the specific aircraft and engine being flown using strip chart recorders, computer-formatted displays, 
and indicator lights providing data from instrumentation on board the aircraft (Fig. 1). Table 1 shows a list of representative propulsion system instrumentation for a research program not involving experimental propulsion system elements; those parameters designated "flight mandatory" indicate instrumentation that must be operational for flight testing. Formatted displays provide digital values of the main propulsion system instrumentation parameters.

Table 1. X-29A representative propulsion system instrumentation list.

\begin{tabular}{lc}
\hline \multicolumn{1}{c}{ Parameter } & $\begin{array}{c}\text { Flight } \\
\text { mandatory }\end{array}$ \\
\hline Inlet temperature & $\times$ \\
Fan speed & $\times$ \\
Core speed & $\times$ \\
Compressor discharge pressure & \\
Main fuel flow & \\
Main ignitor lead temperature & \\
Flame sensor temperature & \\
Turbine discharge pressure & \\
Turbine discharge temperature & $\times$ \\
Afterbumer fuel flow & \\
Afterburner ignitor lead temperature & \\
Exhaust nozzle area & \\
Nozzle LVDT temperature & \\
Power lever angle position & \\
Engine fuel pressure & $\times$ \\
Engine fuel temperature & $\times$ \\
Engine lubrication pressure & $\times$ \\
Fuel tank pressure & $\times$ \\
Fuel tank temperature & $\times$ \\
\hline \hline
\end{tabular}

Each mission control center strip chart recorder provides eight channels of analog information. Typically, the propulsion engineer monitors two of these recorders for both trends and limits. A representative list of some of the parameters displayed on these strip chart recorder channels is provided in Table 2.

Indicator lights are used to monitor system status or to indicate parameters that are out of limits. The number of indicator lights used for propulsion system monitoring varies from program to program. A list of representative limits that might be monitored are included in Table 3.

Currently, engine monitoring is donc by senior-level propulsion engineers and operations engincers in the
Table 2. Representative strip chart recorder parameter list.

\begin{tabular}{ll}
\hline \multicolumn{1}{c}{ Parameter } & \multicolumn{1}{c}{$\begin{array}{c}\text { Parametcr } \\
\text { designation }\end{array}$} \\
\hline Fan speed & N1 \\
Core speed & N2 \\
Compressor discharge pressure & Ps3 \\
Main fuel flow & wf \\
Turbine discharge pressure & Pt5 \\
Turbine discharge temperature & tt5 \\
Afterbumer fuel flow & wf \\
Exhaust nozzle area & A8 \\
Power lever angle position & PLA \\
Engine lubrication pressure & ELube P \\
\hline \hline
\end{tabular}

Table 3. Representative indicator light list.

\begin{tabular}{lc}
\hline \hline \multicolumn{1}{c}{ Parameter } & Indication \\
\hline Fan speed & $>\mathrm{N} 1_{\max }$ \\
Core speed & $>\mathrm{N} 2_{\max }$ \\
Turbine discharge temperature & $>\mathrm{T} 5_{\text {lim }}$ \\
Engine fuel temperature & $>\mathrm{T}_{\text {eng }}$ \\
Fuel tank pressure & $<\mathrm{P}_{\text {tank }_{\text {min }}}$ \\
Engine lubrication pressure & $<\mathrm{P}_{\text {lube }_{\min }}$ \\
Engine skin temperature & $>\mathrm{T}_{\text {skin }_{\text {max }}}$
\end{tabular}

control room and by pilots in the cockpit. Strip charts, CRT's with both digital and graphic data, waming lights, analog gauges, and color panels are all monitored in the control room or similar facility while the pilot monitors his engine gauges in the cockpit.

As can be seen in Tables 1 and 2, the total number of parameters and conditions that must be monitored is not overwhelming, but there is a sufficient number so that a novice would have difficulty providing adequate real-time monitoring. The task of monitoring individual parameters and conditions is only one part of the propulsion system engineer's responsibility. Additionally, the propulsion engineer must also recognize and correctly identify a number of systemslevel anomalies that require understanding of a pattem in several parameters simultaneously. The recognition of a systems-level anomaly and the correct identification of that condition is essential for a corrective or preventative action and for communication with the pilot.

Another problem is that the control rooms are usually limited in the number and type of strip 
charts, cathode-ray tube (CRT) displays, and waming lights. As aircraft and engines increase in complexity, changes need to be made to these displays.

In order to ease some of the burden on the propulsion engineer, the NASA Ames Research Center's Dryden Flight Research Facility has been investigating methods to aid in the monitoring process. Expert systems provide a means of increasing the propulsion engineer's productivity by taking over some of the monitoring functions. By using expert system's technology, the experience of several propulsion engineers can be used.

This work was based on knowledge gained from previous work done on an expert system flight status monitor $^{1-3}$ and is similar in function to the expert system for shuttle mission control. The program documented here was developed to support the F-18 highangle-of-attack research vehiclc program.

This paper describes a preliminary version of an expert system engine monitor that aids the propulsion engineer with many monitoring tasks. In order to evaluate the preliminary version, data from the F404 engine in the X-29A forward-swept wing was used.

\section{System Description}

\section{Engine Description}

The F404 engine is a low bypass axial-flow turbofan with afterburner. The three-stage fan (low pressure compressor) is driven by a single-stage turbine. Approximately one-third of the fan discharge air is bypassed to the afterbumer for combustion and cooling. The seven-stage, high-pressure compressor is also driven by a single-stage turbinc. The first- and secondstage compressor stators are variable. Fourth-stage compressor air is used by the engine's anti-ice system. A set of variable inlet guide vanes are mounted in front of both the fan and compressor to direct the inlet air at the best angle for the existing engine operation.

Atomized fuel and compressor discharge air is mixed and ignited in the combustion chamber. These ignited gases then pass through the compressor and fan turbines and out the engine exhaust. Afterbumer operation uses added atomized fuel mixed with the compressor discharge gases and the bypass fan discharge air to produce additional thrust. The military (nonafterbuming) thrust of each engine is approximately $10,700 \mathrm{lb}$ with maximum afterbumer thrust in the $16,000-1 b$ class.
The electrical control assembly, variable exhaust nozzles, main fuel control, and afterbumer control provide coordinated operation of the engine throughout the flight envelope. The engine accessory gearbox, driven by the compressor rotor, powers the lubrication and scavenge oil pumps, variable exhaust nozzle power unit, alternator, main fuel pump and control, and afterbumer fuel pump and control.

During development there was no available F-18 data to test the intelligent computer assistant for engine monitoring (ICAEM). The only F-404 engine data available at the time was from the $X-29$. Since the $X-29$ has only one engine as opposed to two engines for an F-18, telemetry data was mapped to both engine displays (Figs. 5-6). In this way actual flight data could be used for testing ICAEM.

\section{Current Monitoring System}

Figure 2 shows how monitoring is currently being done at Ames-Dryden. Radar tracking and telemetry tracking devices pass information to the telemetry and radar acquisition processing system. Data is then transmitted to the control room to drive CRT displays, indicator lights, strip chart recorders, and color panels. There is much data, but little information. The propulsion engineer is required to process the data into useful information. Since the knowledge required to transform the data into information is in the engineer's mind, a senior-level propulsion engineer is required to perform this task.

\section{ICAEM Description}

Figure 3 shows how monitoring is done with ICAEM. Telemetry and radar information are received as before. However, rather than having data sent to different devices as before, real-time data are transmitted to a single workstation through a local area network using a standard protocol.

There are many advantages to the new system. The most important advantage is that the programmable workstation has the capability to put some of the engineers' knowledge into the system. This is done through the use of expert systems which use the declarative knowledge contained in rules that evaluate the system being monitored. In this way data, as well as useful information, is displayed to the user. Also, use of programmable workstations for graphic displays substantially reduces the workload, allows for sophisticated graphics without impacting the critical acquisition software, and provides greater flexibility in display design and reconfiguration. ${ }^{4}$ 


\section{Description of Internal Structure of ICAEM}

The overall intemal structure of ICAEM is shown in Fig. 4. The main portion of ICAEM is a program that acts as an interface between the telcmetry data being provided by way of Ethernet and the expert system. Once given data, the expert system decides if any condition exists that the engineer needs to know. If so, that information is sent to another program that displays the necessary information to the engineer.

When telemetry data is received, the main program asserts a fact into a fact base in the expert system. Once enough facts are generated to match the conditions of a rule, the rule is "fired." For example, consider a rule in the expert system such as one to monitor a potential hung start:

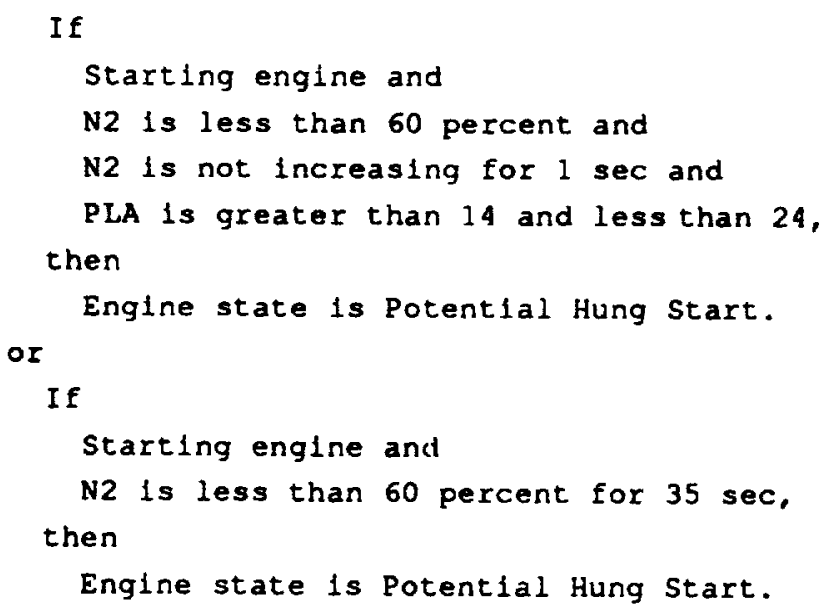

This warns the engineer of the danger of a hung start before the hung start actually takes place. The main program receives telemetry data for many parameters including those needed for the above rules. It then asserts facts into the expert system fact base. The expert system looks at all the facts being asserted, and if every condition in the rule is satisfied, it "fires" that rule. The consequent of the rule is then passed to the display program so that the engineer will receive the necessary information. If any condition is not satisfied, the rule is not fired.

The expert system used in ICAEM is the C Language Production System (CLIPS) inference engine produced by the Mission Planning and Analysis Directorate of NASA's Johnson Space Center. ${ }^{5}$ The primary representation methodology used in CLIPS is a forward-chaining rule language based on the Rete algorithm. ${ }^{6}$ CLIPS was chosen because it was written in the " $C$ " language and was designed to be embedded within an application. This is a very important feature for this project because of the need to interface the in- ference engine to a real-time application written in a procedural language. Other expert systems exist but provide no means of interfacing since they provide a "total environment."

Using the rule-based expert systems approach allows gathering and implementing the propulsion engineer's knowledge very quickly, which in turn allows quick feedback on the quality of the knowledge captured in the expert system and quickly raises the quality level with just a few iterations.

\section{Overview of ICAEM's Capabilities}

\section{Determining Engine Operational State}

The main functions to be performed by the propulsion system expert system are monitoring, anomaly classification, and both nomal and recovery procedure aiding.

The monitoring task involves the following functions:

- Determination of engine operating state

- Detection of parameters whose value has exceeded limits

- Detection of the rates of change of parameters

- Prediction of trends

- Timing of duration of parameters outside of limits

This information is then used to identify any anomalous system behavior (see Identification of Anomalies) and, when this behavior corresponds to a predefined pattern of behavior, to identify the type of anomalous behavior being exhibited by the propulsion system. Two types of anomalous behavior must be identified by the system: single parameter and systematic. Single parameter anomalies are those in which a parameter exceeds a limit or exceeds a limit for too long a period. Systematic anomalies are those in which the propulsion system exhibits anomalous behavior in multiple parameters in some pattern.

The system is partitioned by engine states as follows:

- Ground start

- Normal ground operation

- Take-off 
- Normal flight operation

- Airstart

Partitioning in this way allows partitioning the rules in a similar manner so that only the rules within each partition will fire at one time, thus significantly reducing the processing time for the expert system.

Within each of the above partitions, ICAEM monitors only those parameters and rules associated with that state. In the ground start state, for example, ICAEM monitors for engine start, power level angle (PLA) to ground idle, lite-off and normal start, hung start, or hot start.

Given any state, ICAEM monitors only those parameters necessary. Some parameters, however, are always monitored whether or not they are displayed. For instance, engine lubrication pressure (ELube $P$ ) is a parameter that is always monitored, whereas $\mathrm{Nz}$ is only monitored when $E \perp$ Lube $P$ is out of limits (that is, ELube $P$ is usually disreganded if $\mathrm{Nz}$ is less than $0.5 \mathrm{~g}$ 's).

\section{dentification of Anomalies}

The primary function of propulsion system monioring is the detection of system anomalies. These nomalies fall into the categories of "system anomaes" and "engine anomalies." System anomalies are bnormal operation within the total propulsion system it external to the gas generator and afterbumer. Enne anomalies are those that occur within the gas genator. Whenever any of these anomalies occur, they ust be correctly identified and appropriate corrective tion taken.

The anomalous system conditions that must be deted are:

- excessive engine fuel temperature

high or low engine fuel pressure

engine compartment overheating

low or high oil pressure

excessive oil temperature

ie anomalous engine conditions that must be ded are:

stagnation
- hot start

- hung start

- engine overtemp

- engine stall

- engine failure

- engine overspeed

- afterbumer malfunction

- engine flameout

Some of these anomalies are not presently monitored. Methods to monitor them are still in the development stage. At present, monitoring is being done for hot start, hung start, engine stall, and engine overtemp for the engine anomalies, and low lubrication pressure for the system anomalies.

\section{Procedural Aiding}

As stated earlier, it was convenient to distinguish between five specific conditions: ground start, normal ground operation, take-off, normal flight operation, and airstart. Associated with each of these conditions or "modes" is a set of anomalous conditions to watch for and a corresponding procedure for each anomaly.

In the ground start mode, monitoring is being done for a hot start and a hung start. If there is a hot start or a hung start, a window will appear at the top of the display containing two sets of procedures. One is a ground station procedure for this particular condition and the other is a cockpit procedure. These procedures are taken directly from the flight manual. Figure 6 shows the procedures display for a stall. Besides having the ability to bring up the procedures automatically on an anomaly, the user also has the ability to bring up any procedure he wishes in order to review it at any time.

\section{Information Displays}

The display or user interface serves to enhance the propulsion engineer's processing of data. Typically, a propulsion engineer must process a textual data screen from which a mental model of the corresponding subsystems is built. ICAEM reduces the mental processing time and reduces the data monitoring load.

The ICAEM display is partitioned into three major sections (Fig. 5). The bottom portion of the display shows a cross-sectional view of two engines-left 
shows a cross-sectional view of two engines-left and right. This section of the display shows parameters that are always monitored. Thermometer-like displays are at respective engine stations. The right vertical bar (blue) indicates the actual value of a given parameter while the left vertical bar (green) indicates a predicted value of the same parameter. This predicted value is based on a number of previous data samples and indicates a trend (for example, if the predicted value is consistently higher than the actual value, it indicates the value has been increasing). The box containing digital data at each station will change to yellow when the parameter is near a predetermined limit and will tum red when the parameter reaches that limit.

The center display is two colored horizontal bars containing text. These bars show the actual state of the engine. Any nominal condition is displayed with a green background, while a warning condition or a condition of potential concem is displayed with a yellow background. Any serious condition is displayed with a red background. The center display is used to monitor the status of the engine. As shown previously, in a normal ground start the following statuses would be shown as they occur:

- Starting engine

- PlA to ground idle

- Lite-off

- Normal start

The top portion of the display is used to show userrequested information. Using a mouse, the user may request strip charts on any parameter desired and/or pop up a display with a procedure on it, or tum off a parameter believed to be an erroneous sensor or faulty telemetry data.

The strip chart displays resemble conventional penand-ink recorders (Fig. 5). The engineer may call up as many parameters on this display as desirednot just predetermined parameters as before. Signal traces are displayed and tagged with limits. The strip charts demonstrate how a current capability need not be lost but can be provided in a better form while still making use of the propulsion engineer's training and experience.

The top portion of the display is also used for procedures (Fig. 6). At any time, the user may bring up a display that shows the procedures required of the engineer on the ground and the necessary procedures required of the pilot in any given anomalous situation. The procedural displays also pop-up automatically when an anomaly is encountered by the expert system.

There are conceivably times when a propulsion engineer is aware that some data must be disregarded. It may be obvious from the data displayed that a certain sensor is bad and the information received is erroneous. In that case, the engineer can, in effect, tum off the sensor. The expert system stops using that parameter's information, and data for that parameter is not displayed.

\section{Conclusion}

This document presents a preliminary version of a propulsion system expert system that was developed for monitoring and procedural aiding in support of the F-18 high-angle-of-attack research vehicle program. This expert system is designed to operate as an "expert aide" to an engineer with little or no experience in propulsion system monitoring. The goal of this expert system development project is to relieve the propulsion engineer of the time-consuming, but necessary, task of propulsion system monitoring on flight programs with nonexperimental engines. The intelligent computer assistant for engine monitoring provides a better monitoring environment because it uses the knowledge and experience of several propulsion engineers. It is always attentive and never distracted as a human may be. And the system displays information, not raw data, therefore enhancing safety of flight and improving the engineer's efficiency in propulsion system monitoring.

\section{References}

'Duke, Eugene L. and Regenie, Victoria L., Description of an Experimental Expert System Flight Status Monitor, NASA TM-86791, 1985.

${ }^{2}$ Disbrow, James D., Duke, Eugene L., and Regenie, Victoria L., Development of a Knowledge Acquisition Tool for an Expert System Flight Status Monitor, AIAA paper 86-0240, 1986.

${ }^{3}$ Regenie, Victoria A. and Duke, Eugene L., Design of an Expert System Flight Status Monitor, NASA TM86739, 1985.

${ }^{4}$ Nesel, Michael C. and Hammonds, Kevin R., RealTime Test Data Distribution and Display, NASA TM100424, 1988. 
${ }^{5}$ CLIPS Reference Manual Version 4.2 of CLPS, Artificial Intelligence Section, Lyndon B. Johnson Space Center, JSC-22948, April 1988.

${ }^{6}$ Forgy, Charles L., "Rete: A Fast Algorithm for the Many Pattern/Many Object Pattem Match Problem," Artificial Intelligence 19 (1982), pp. 17-37.

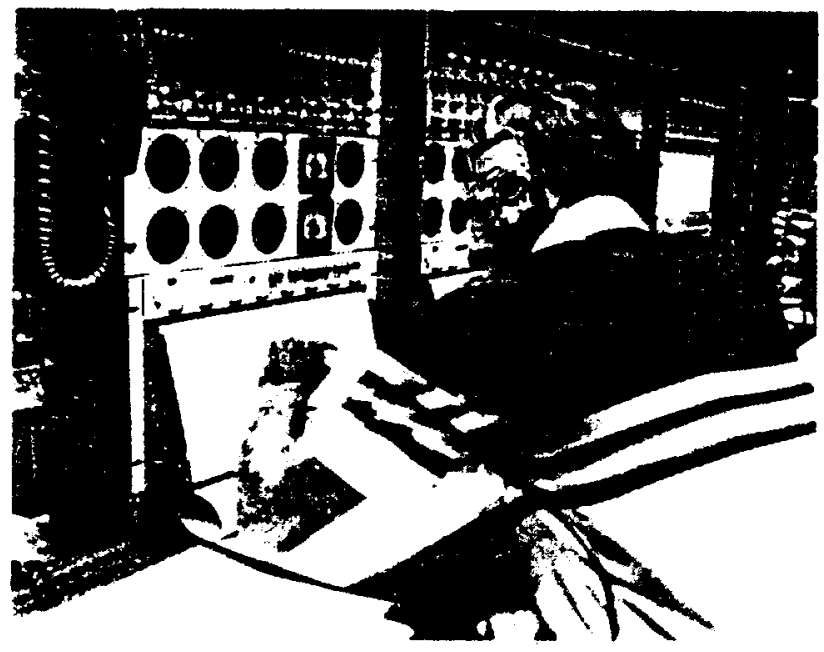

ECN 15891

Fig. 1 Control room.

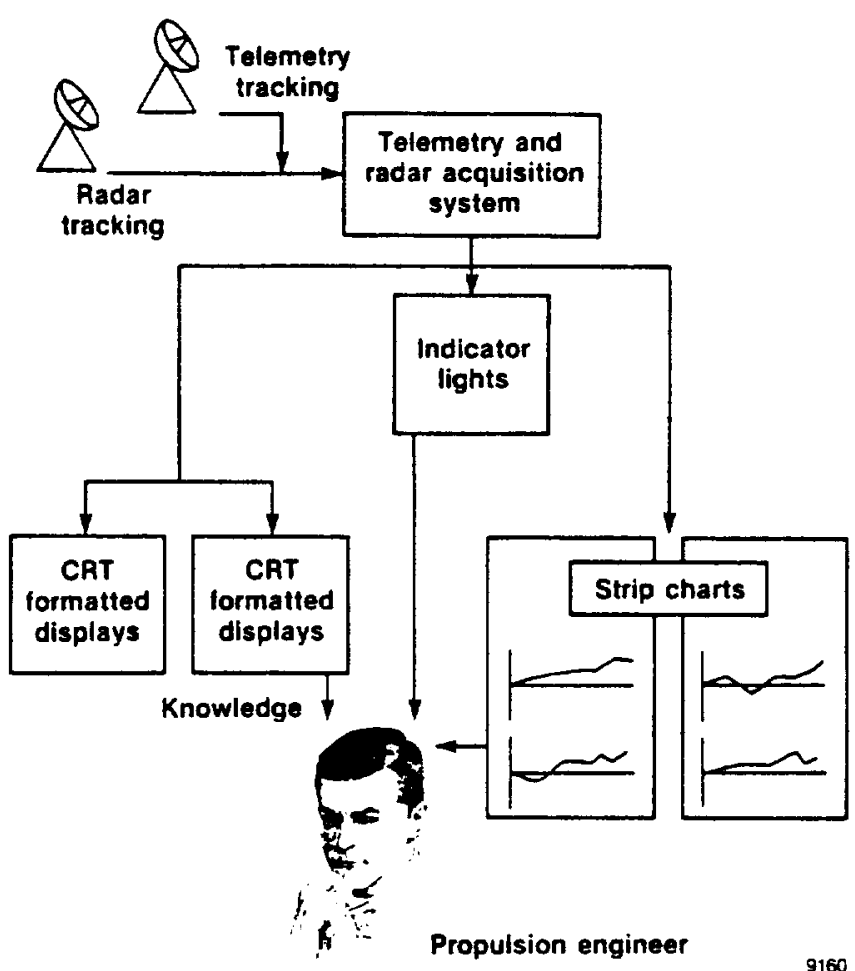

Fig. 2 Current system.

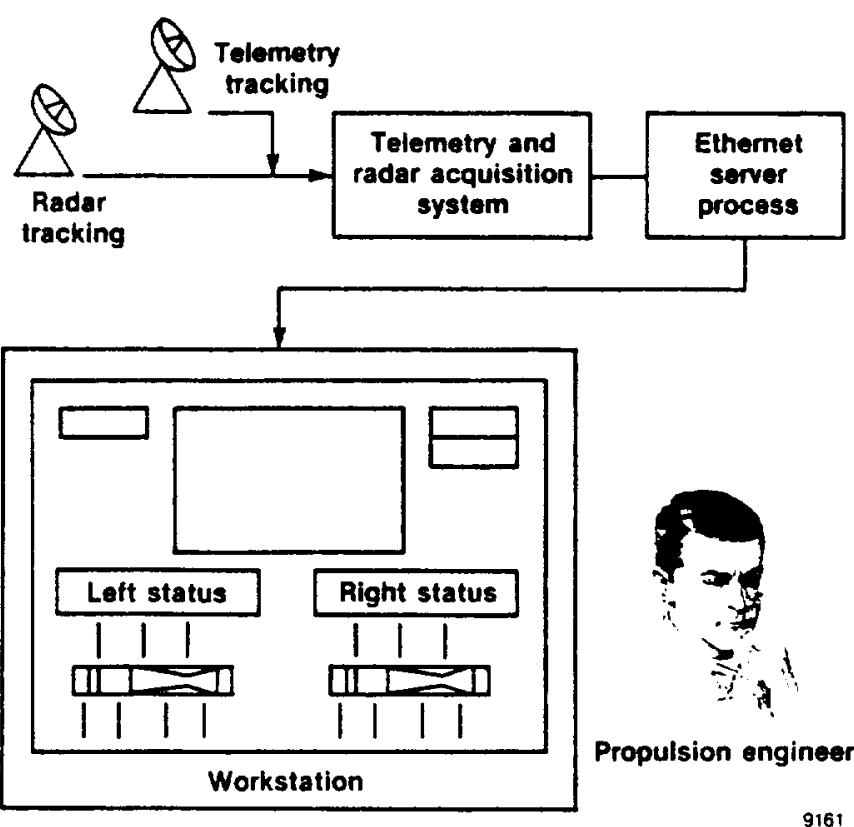

Fig. 3 ICAEM system.

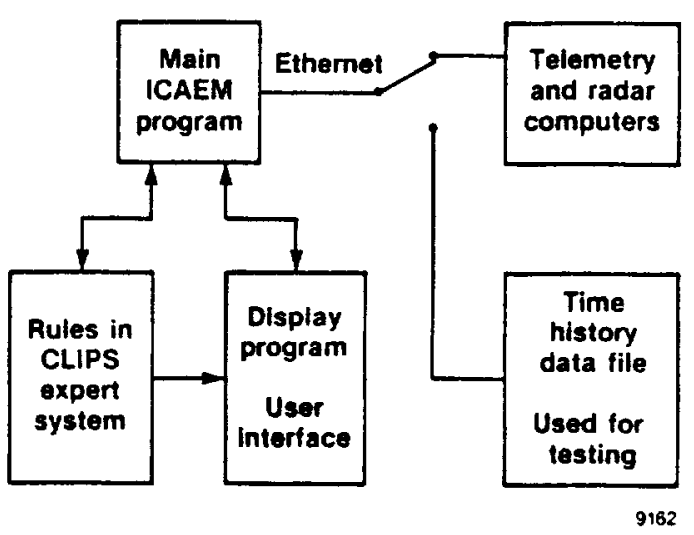

Fig. 4 Intemal structure. 
Flight conditions

Altitude 2239

\begin{tabular}{|l}
\hline Mach no. $\quad 0.00$ \\
\hline
\end{tabular}

\begin{tabular}{|ll|}
\hline Alpha $\quad 0.00$ \\
\hline
\end{tabular}
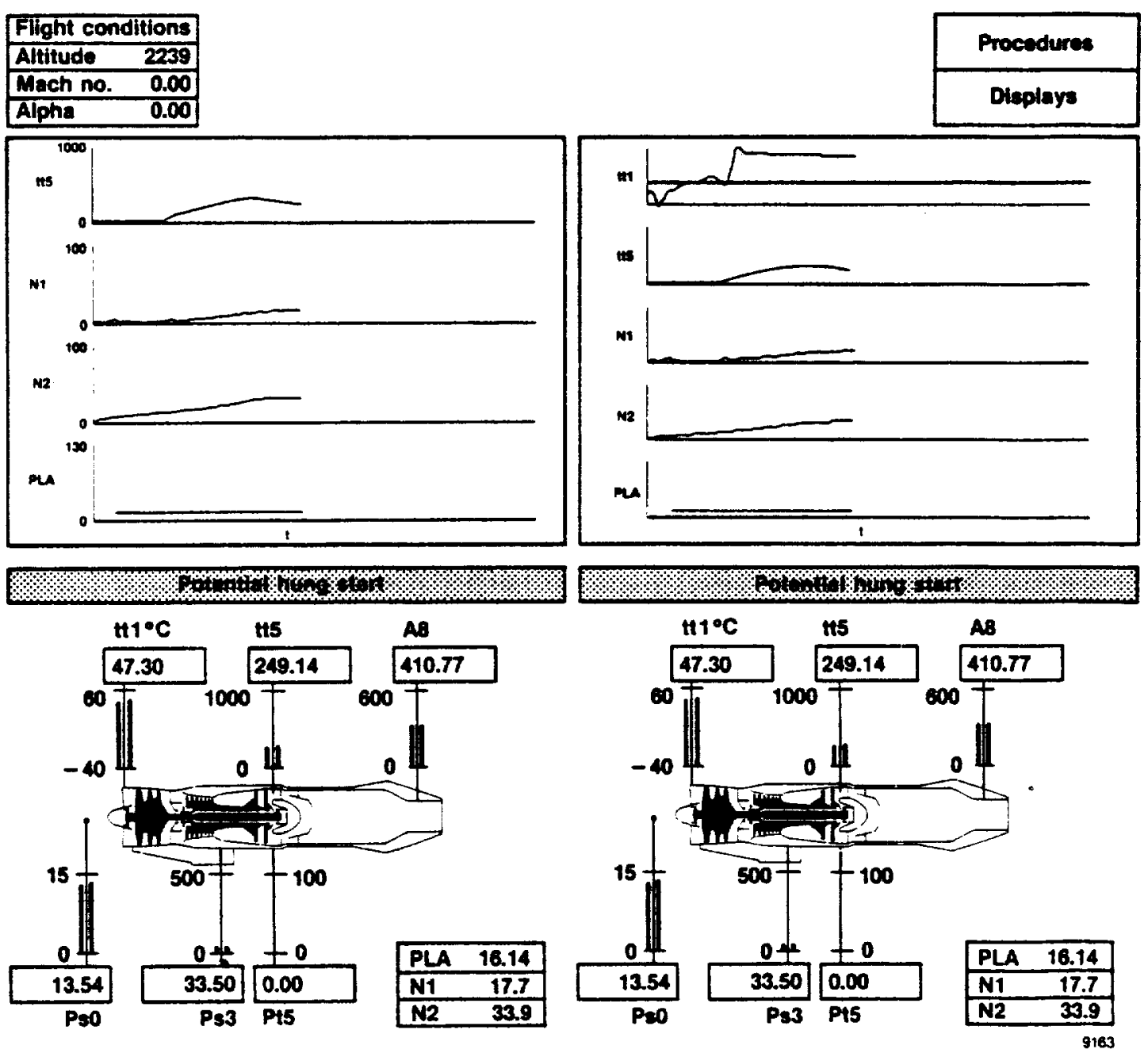

Fig. 5 Display with strip charts. 


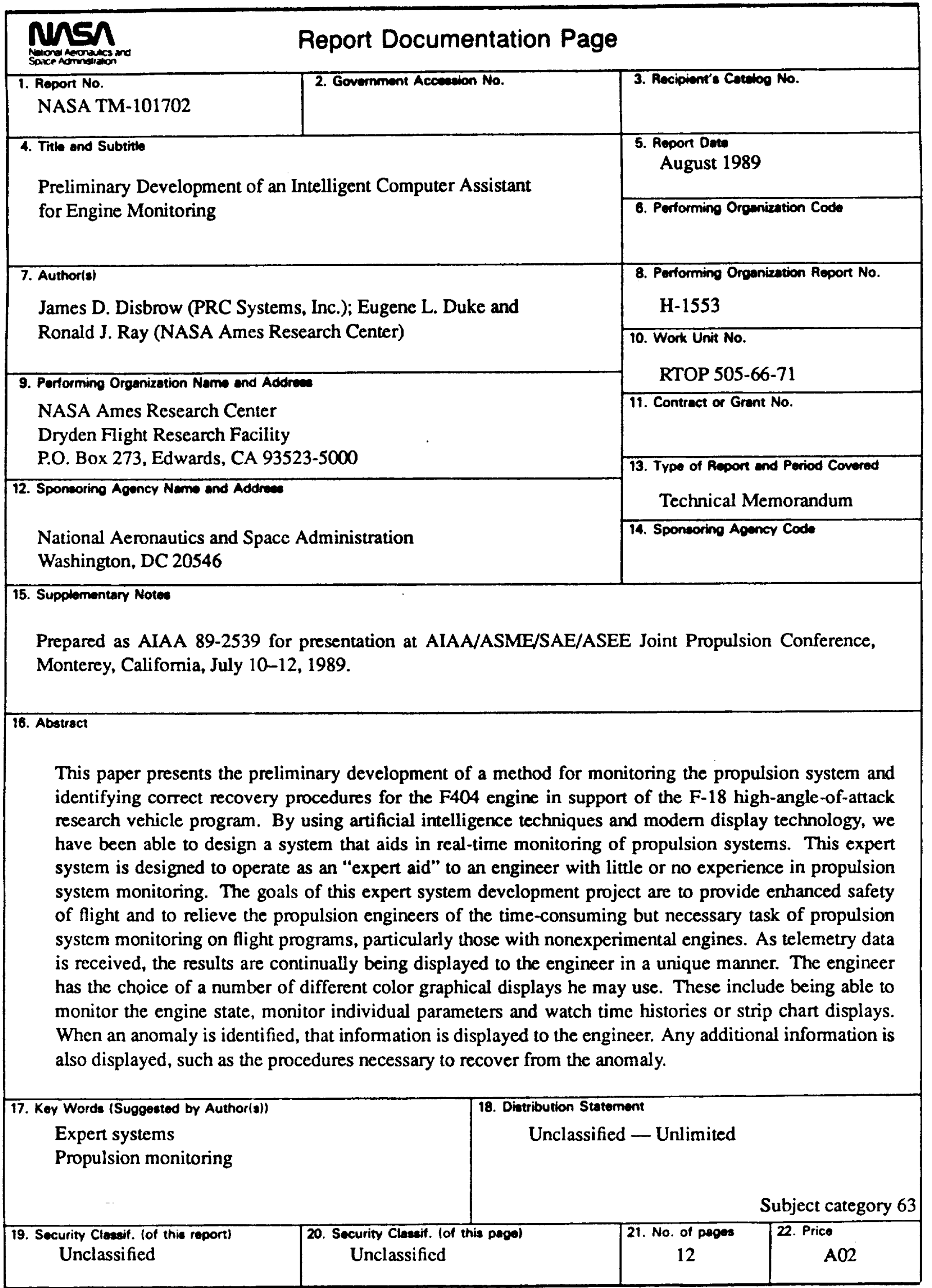




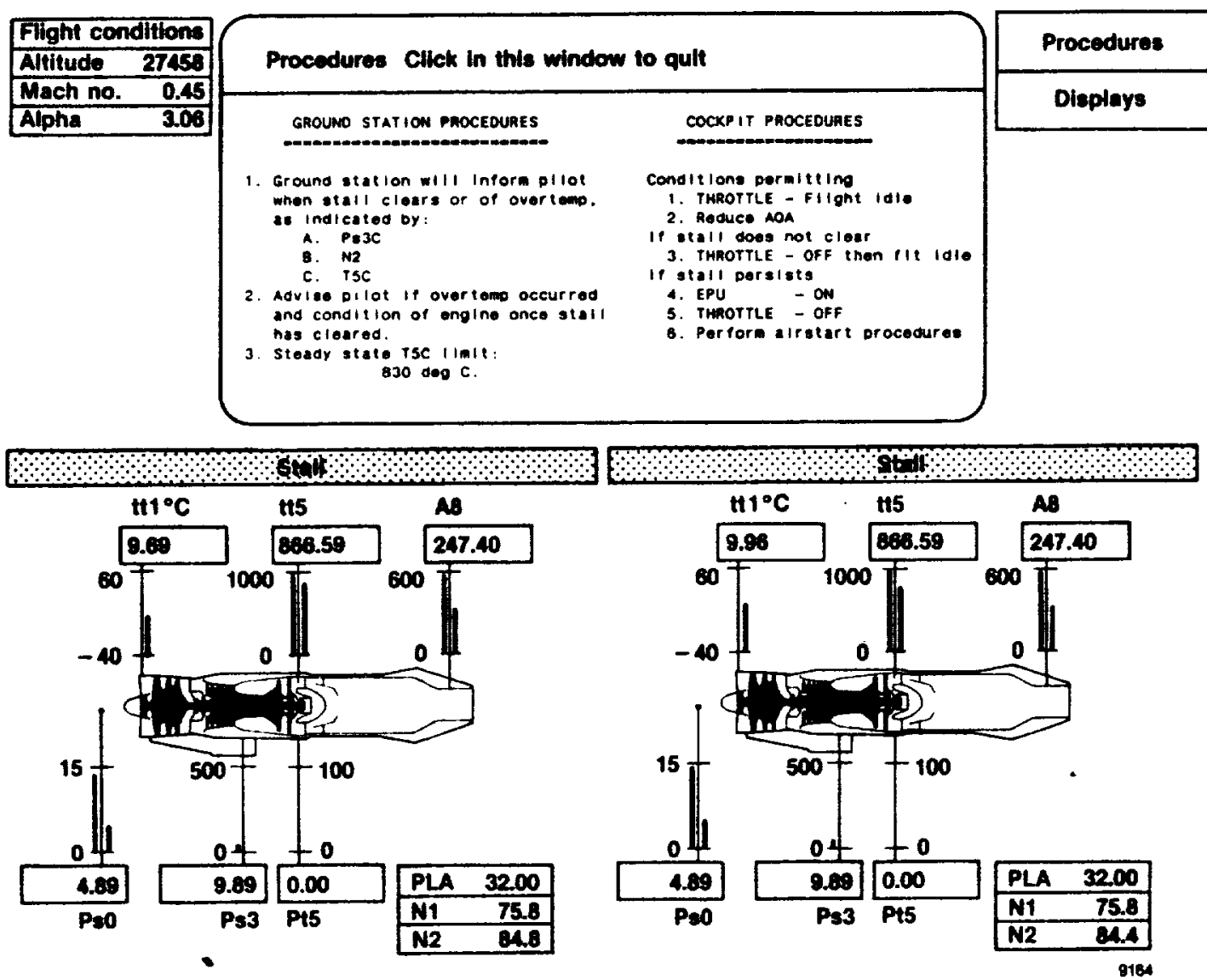

Fig. 6 Display with procedure. 
$-1$

.

i

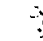


